\title{
Incorporated W Roles on Microstructure and Properties of W-C:H Films by a Hybrid Linear Ion Beam Systems
}

\author{
Peng Guo, Peiling Ke, and Aiying Wang \\ Key Laboratory of Marine Materials and Related Technologies, Zhejiang Key Laboratory of Marine Materials and \\ Protective Technologies, Ningbo Institute of Materials Technology and Engineering, Chinese Academy of Sciences, Ningbo 315201, China
}

Correspondence should be addressed to Aiying Wang; aywang@nimte.ac.cn

Received 9 October 2013; Revised 21 November 2013; Accepted 21 November 2013

Academic Editor: Myoung-Woon Moon

Copyright (C) 2013 Peng Guo et al. This is an open access article distributed under the Creative Commons Attribution License, which permits unrestricted use, distribution, and reproduction in any medium, provided the original work is properly cited.

\begin{abstract}
$\mathrm{W}$-incorporated diamond-like carbon (W-C:H) films were fabricated by a hybrid beams system consisting of a DC magnetron sputtering and a linear ion source. The $\mathrm{W}$ concentration (1.08 31.74 at.\%) in the film was controlled by varying the sputtering current. The cross-sectional topography, composition, and microstructure of the W-C:H films were investigated by SEM, XPS, TEM, and Raman spectroscopy. The mechanical and tribological properties of the films as a function of $\mathrm{W}$ concentration were evaluated by a stress-tester, nanoindentation, and ball-on-disk tribometer, respectively. The results showed that films mainly exhibited the feature of amorphous carbon when $\mathrm{W}$ concentration of the films was less than 4.38 at.\%, where the incorporated W atoms would be bonded with $\mathrm{C}$ atoms and resulted in the formation of $\mathrm{WC}_{1-x}$ nanoparticles. The $\mathrm{W}-\mathrm{C}: \mathrm{H}$ film with 4.38 at.\% W concentration showed a minimum value of residual compressive stress, a higher hardness, and better tribological properties. Beyond this $\mathrm{W}$ concentration range, both the residual stress and mechanical properties were deteriorated due to the growth of tungsten carbide nanoparticles in the carbon matrix.
\end{abstract}

\section{Introduction}

Diamond-like carbon film (DLC) is a metastable form of amorphous carbon with a certain dominant $\mathrm{sp}^{3}$ bonding. Due to its unique properties such as high hardness, low friction coefficient, good chemical inertness, and the optical transparency in a wide range of VIS-IR, DLC film has been used as protective coatings in many industrial fields [1]. However, high residual stress is the major drawback of DLC films for its wider practical application [2-6]. Immense amounts of concrete research have shown that the incorporation of metal elements, such as $\mathrm{Mo}, \mathrm{Cu}, \mathrm{Al}, \mathrm{Cr}$, and $\mathrm{W}$, is one of the good methods to decrease the internal stress of DLC films [7-12]. As one of the doped metal elements, W-incorporated DLC films (W-C:H) have been received considerable attention both in scientific research and industrial fields of carbon based materials [13-19]. The properties and structure of $\mathrm{W}-\mathrm{C}: \mathrm{H}$ films prepared by the process combining reactive magnetron sputtering with plasma source ion implantation were reported by Baba and coworkers [20]. Takeno et al.
[21] investigated the electrical properties and structure of $\mathrm{W}-\mathrm{C}: \mathrm{H}$ films prepared by radio frequency plasma enhanced chemical vapor deposition, and a resistive superconducting transition was discovered in their report. Wang et al. [22] reported a rapid increase and a gradual decrease in the residual stress of DLC films prepared by end-Hall-type ion gun with increasing $\mathrm{W}$ concentration. But considering the characterization complexity of carbon bonds caused by the incorporated $\mathrm{W}$ atoms and the easier controlled synthesis with a wide range of $\mathrm{W}$ concentration, the new deposition technique of hybrid ion beam system is demanded and the relationship between properties and structure of W-C:H films as a function of $\mathrm{W}$ concentration lacked study.

Ion beam sources have been widely used in the field of science and industry such as substrate cleaning, DLC film deposition and surface modification [20, 23-29]. Anode layer type linear ion source (ALIS) is a kind of closed drift type linear ion sources promoted by the plasma acceleration technology of the aerospace thruster [30]. As a large-area surface treatment technique, the ALIS is a gridded ion source 
with simple electrode structure, which can provide a higher ion beam current density and readily be scaled to any desired length [30-34].

In this work, a hybrid ion beam deposition system consisting of a DC magnetron sputtering and an ALIS is employed to fabricate the W-C:H films, the used method focused on the $\mathrm{W}-\mathrm{C}: \mathrm{H}$ films with different $\mathrm{W}$ concentration, and the films were prepared by a unique hybrid ion beam system. The mechanical properties and structure of the films as a function of $\mathrm{W}$ concentration were studied. The results indicated that the DLC films with relatively low stress and high hardness could be achieved by doping a low concentration of $\mathrm{W}$ atoms.

\section{Experiment}

Si (100) wafer of thickness $710 \pm 15 \mu \mathrm{m}$ was used as the substrate material. A thin Si (100) wafer of thickness $250 \pm 5 \mu \mathrm{m}$ was also used as substrate to accurately estimate the internal residual stress. The substrate was cleaned ultrasonically in acetone and dried in air before deposition. The W-C:H film was prepared on Si substrate by a hybrid ion beams deposition system consisting of a DC magnetron rectangular sputtering with a $100 \mathrm{~mm}(\mathrm{~W}) \times 400 \mathrm{~mm}(\mathrm{~L}) \mathrm{W}$ target (99.95\%) and a $380 \mathrm{~mm}$ (L) anode layer type linear ion source (ALIS) [35]. The substrates were sputter-cleaned for 20 mins using Ar ions with a pulsed bias voltage of $-100 \mathrm{~V}$. The base pressure was evacuated to a vacuum of about $2 \times 10^{-5}$ Torr. During film deposition process, hydrocarbon gas $\left(\mathrm{C}_{2} \mathrm{H}_{2}\right)$ was introduced into the linear ion source to obtain the hydrocarbon ions for DLC deposition. The Ar sputtering gas was supplied to the magnetron sputter for $\mathrm{W}$ sputtering. The concentration of tungsten in the films was controlled by varying the sputtering current from 0.9 to $1.5 \mathrm{~A}$. The $\mathrm{C}_{2} \mathrm{H}_{2}$ flux and Ar flux were kept at 10 and $70 \mathrm{sccm}$, respectively, and the work pressure was kept at about $4.0 \times 10^{-3}$ Torr. Typical values of ALIS voltage and current were $1300 \mathrm{~V}$ and $0.2 \mathrm{~A}$, respectively. A negative pulsed bias voltage of $-100 \mathrm{~V}(350 \mathrm{KHz}, 1.1 \mu \mathrm{s})$ was applied to the substrate. The deposition time was 40 mins. For comparison, the pure DLC film was also prepared using ALIS and a negative substrate bias of $-100 \mathrm{~V}$.

The thickness of the deposited films was measured by surface profilometer (Alpha-Step IQ, USA). The crossmorphology of the deposited films was observed by a crosssection SEM (Hitachi S-4800). An X-ray photoelectron spectroscopy (XPS, Thermo Scientific ESCALAB 250) with monochromated $\mathrm{Al} \mathrm{X}$-ray resource was used to characterize the chemical composition, atomic bonds, and microstructure of the films. High-resolution transmission electron microscopy (TEM, Tecnai F20), operated at $200 \mathrm{KeV}$ with a point-to-point resolution of $0.24 \mathrm{~nm}$, was used to clarify the microstructure. Raman spectroscopy (Renishaw inVia-reflex) equipped with a He-Ne laser of $532 \mathrm{~nm}$ exciting wavelength was used to measure the atomic bonds of the films at a detecting range from 600 to $2000 \mathrm{~cm}^{-1}$.

The internal residual stress of the films was calculated using the Stoney equation, and the curvature of film/substrate composite was determined by a laser tester. Mechanical properties were measured using the nanoindenter (MTSG200) with the depth to $200 \mathrm{~nm}$, and the hardness was chosen in a depth of around 1/10 of the coating thickness in order to avoid the contribution of Si substrate to the results. The tribological behaviors of the Si coated by the films were measured on a rotary ball-on-disk tribometer at room temperature with a relative humidity of about $50 \%$ under dry sliding conditions. All the tests were performed at $0.12 \mathrm{~ms}^{-1}$ sliding speed for a distance of $400 \mathrm{~m}$ and the applied load was $5 \mathrm{~N}$.

\section{Results and Discussion}

Figures 1(a) and 1(b) showed the change of $\mathrm{W}$ concentration and average growth rate of the films as a function of the sputtering current, respectively. The $\mathrm{W} / \mathrm{C}$ atomic ratio of the films was determined based on the atomic sensitivity factors and area ratio of the $\mathrm{C} 1 \mathrm{~s}$ to $\mathrm{W} 4 \mathrm{f}$ peaks in XPS spectra of the films. The $\mathrm{W}$ concentration of the films increased from 1.08 to 31.74 at.\% as the sputtering current increased from 0.9 to $1.5 \mathrm{~A}$, as shown in Figure 1(a), while the growth rate of films decreased slightly from about 17 to $15 \mathrm{~nm} / \mathrm{min}$, as seen in Figure 1(b), which may be induced by antisputtering effect of $\mathrm{W}$ atoms with higher kinetic energy at $1.5 \mathrm{~A}$ sputtering current [36]. Noted that, less than the sputtering current of $0.9 \mathrm{~A}$, it was difficult to extract the accurate amount of $\mathrm{W}$ concentration from the XPS spectra because of the serious W target pollution by the ionized carbon precursors. Beyond the case of $1.5 \mathrm{~A}$, the deposited films showed a typical W metallic luster.

Figure 2 showed the cross-sectional SEM images of the films with different $\mathrm{W}$ concentrations. And the films in Figure 2 were marked by double-headed arrows. The images demonstrated similar smooth surface when $\mathrm{W}$ concentration was less than 4.38 at.\% and exhibited the feature of the amorphous structure, which suggested that W-C:H films with W concentration less than 4.38 at.\% kept amorphous features. However, when the $\mathrm{W}$ concentration increased to 31.74 at.\%, the film became rough with emergence of nanoscale particulates in the carbon matrix, as illustrated in Figure 2(d), due to the formation of tungsten carbide phase.

XPS provided the approach to analyze the chemical bonds of the deposited films by C 1s. Figure 3(a) displayed the XPS C 1 s peaks of the pure DLC film and $\mathrm{W}-\mathrm{C}: \mathrm{H}$ films with different $\mathrm{W}$ concentrations. When the $\mathrm{W}$ concentration was less than 4.38 at.\%, the $\mathrm{C} 1 \mathrm{~s}$ spectra were divided into two peaks around $284.6 \mathrm{eV}$ and $286.5 \mathrm{eV}$ corresponding to the typical $\mathrm{C}-\mathrm{C} / \mathrm{C}-$ $\mathrm{H}$ and $\mathrm{C}-\mathrm{O} / \mathrm{C}=\mathrm{O}$ binding energy, respectively [20, 37-39]. However, when the $\mathrm{W}$ concentration increased to 31.74 at. \%, a shoulder peak with a lower binding energy of about $283.5 \mathrm{eV}$ appeared, as shown in Figure 3(b). The peak at $283.1 \sim 283.6 \mathrm{eV}$ is generally assigned to the $\mathrm{W}-\mathrm{C}$ bonds $[18,20,40]$, so it can be deduced that the tungsten carbide was formed in the films with a higher $\mathrm{W}$ concentration.

Figure 4 displayed the plan-view high-resolution TEM images and the corresponding SAED patterns of the pure DLC film and W-C:H films. Similar to the result of pure DLC, Figure 4(b) presented dense and smooth granular contrasts, 


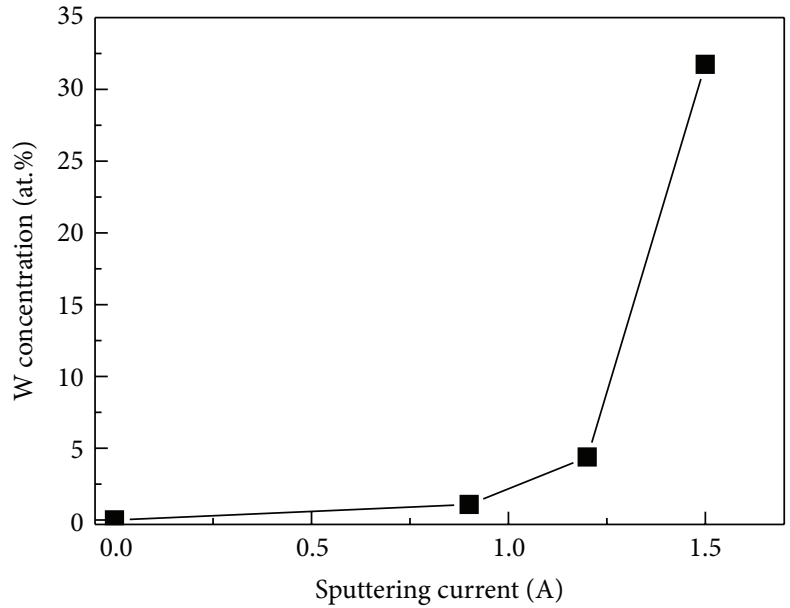

(a)

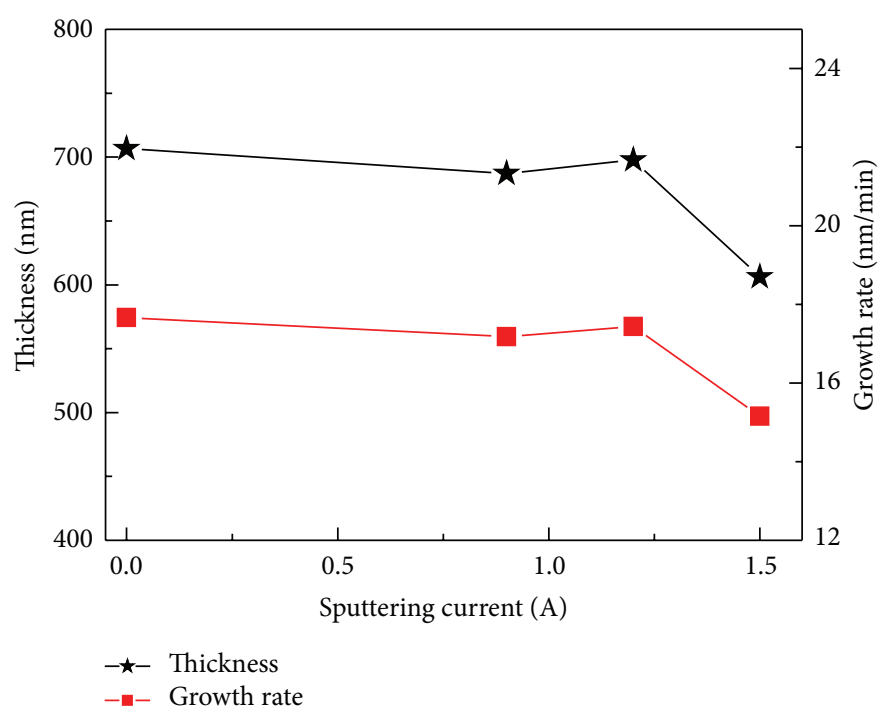

(b)

FIGURE 1: W concentration (a), growth rate and thickness (b) of the films as a function of sputtering current.

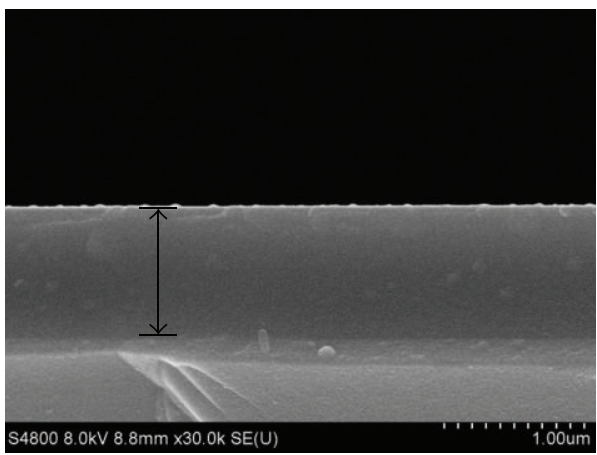

(a)

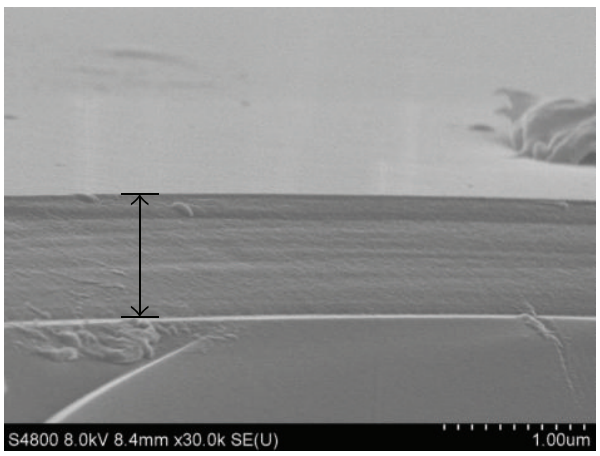

(c)

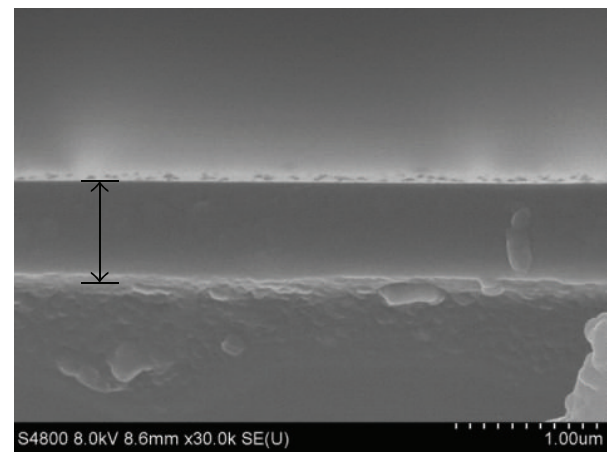

(b)

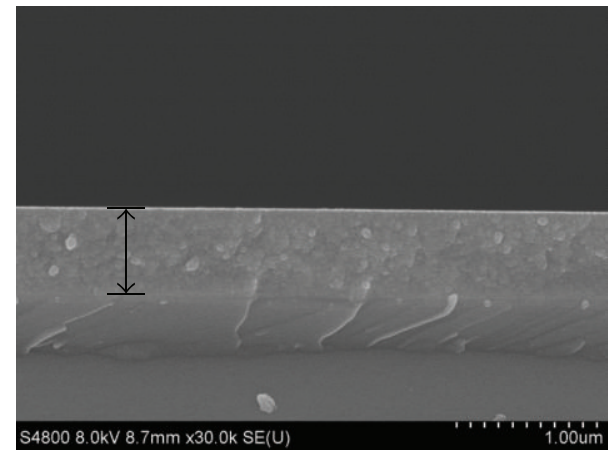

(d)

Figure 2: Cross-sectional SEM images of the pure DLC film (a); films with 1.08 at.\% W (b), 4.38 at.\% W (c), and 31.74 at.\% W (d).

and the corresponding SAED patterns showed a broad and diffuse diffraction halo. It implied that the deposited films essentially formed a typical amorphous structure, and the $\mathrm{W}$ atoms were uniformly distributed and dissolved in the DLC matrix. But for the W-C:H film with 4.38 at.\% W atoms (Figure 4(c)), a few nanoparticles with grain diameter about $5 \mathrm{~nm}$ were found in the film, and more nanoparticles with similar grain diameter could be observed obviously in W-C:H film with 31.74 at.\% W atoms (Figure 4(d)); the corresponding diffraction ring of SAED pattern in Figure 4(d) became much sharper than that in Figure 4(c), suggesting more carbide particles of high crystallinity existed in these films. Figure 4(d) revealed the clear lattice fringes of the nanoparticles 


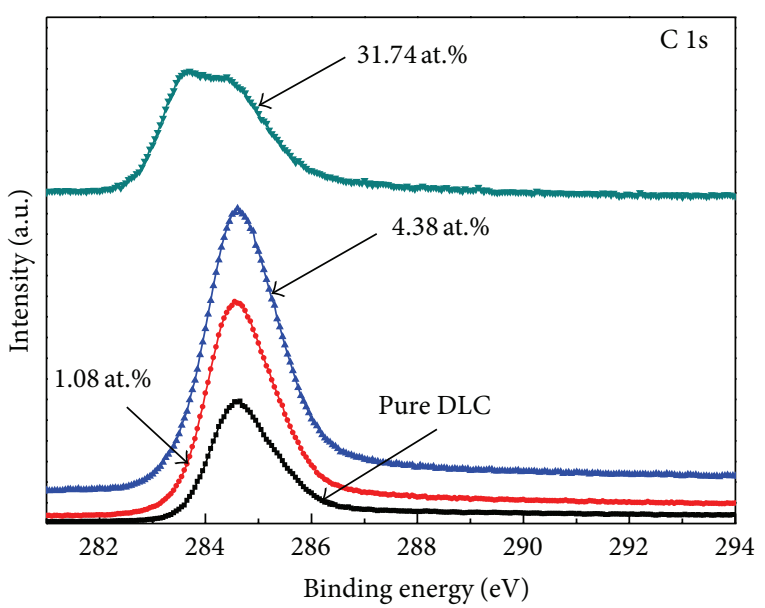

(a)

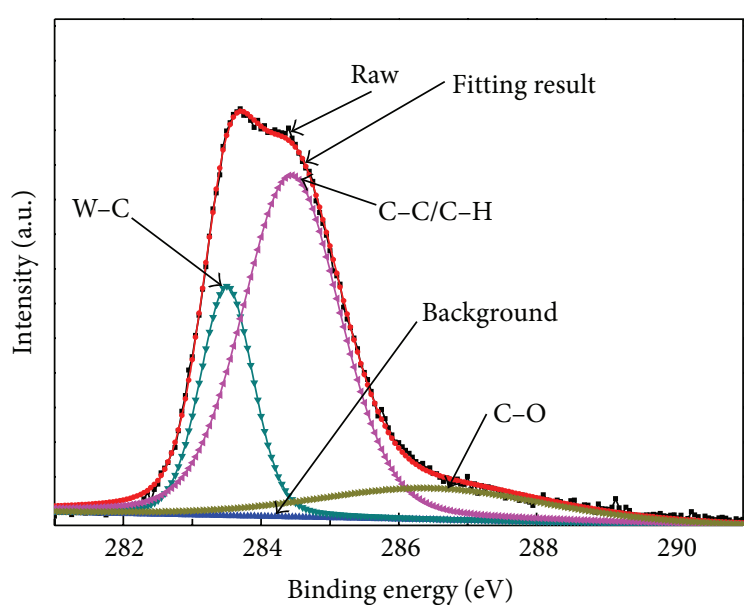

(b)

FIgURE 3: Typical C 1s high-resolution XPS spectra of the films with different W concentration (a), XPS spectra of the films with 31.74 at.\% $\mathrm{W}(\mathrm{b})$.

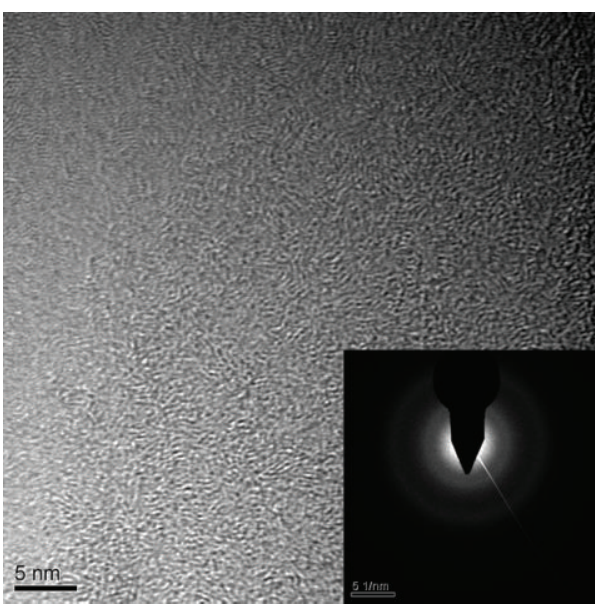

(a)

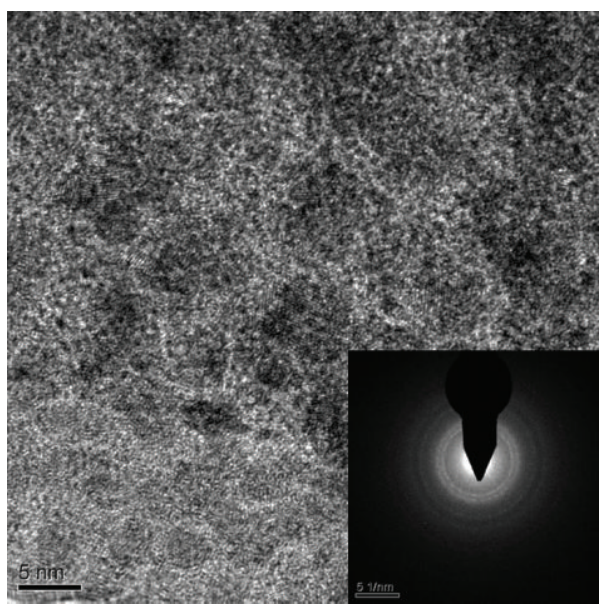

(c)

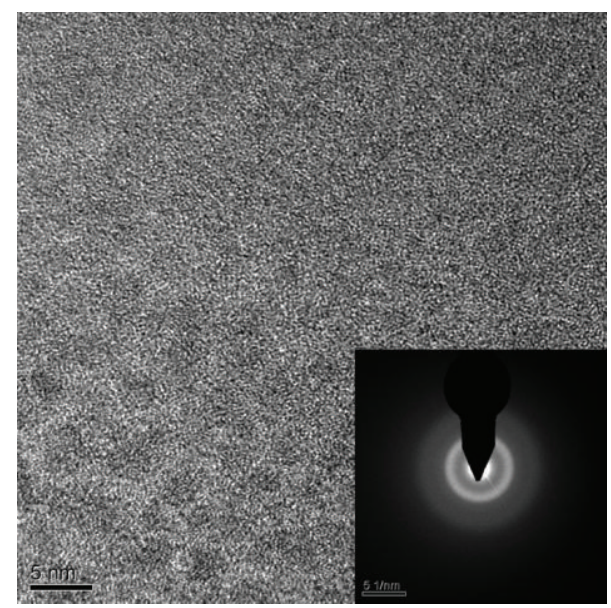

(b)

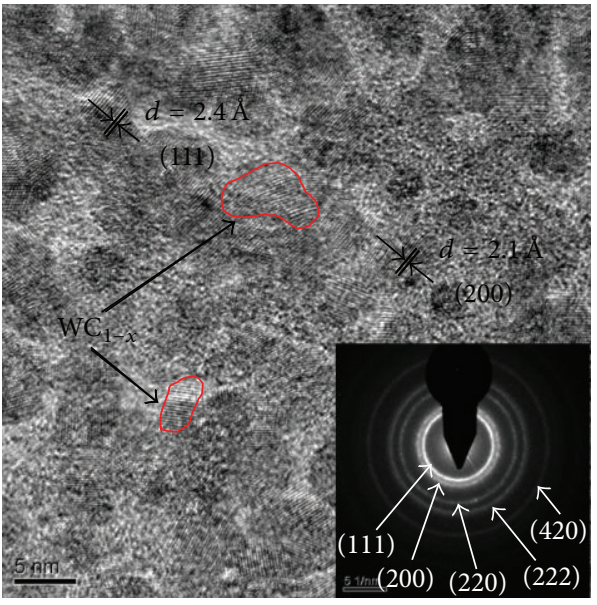

(d)

FIGURE 4: Plan-view high-resolution TEM images and corresponding SAED pattern of the pure DLC film (a); films with 1.08 at.\% W (b), 4.38 at.\% W (c), and 31.74 at.\% W (d). 

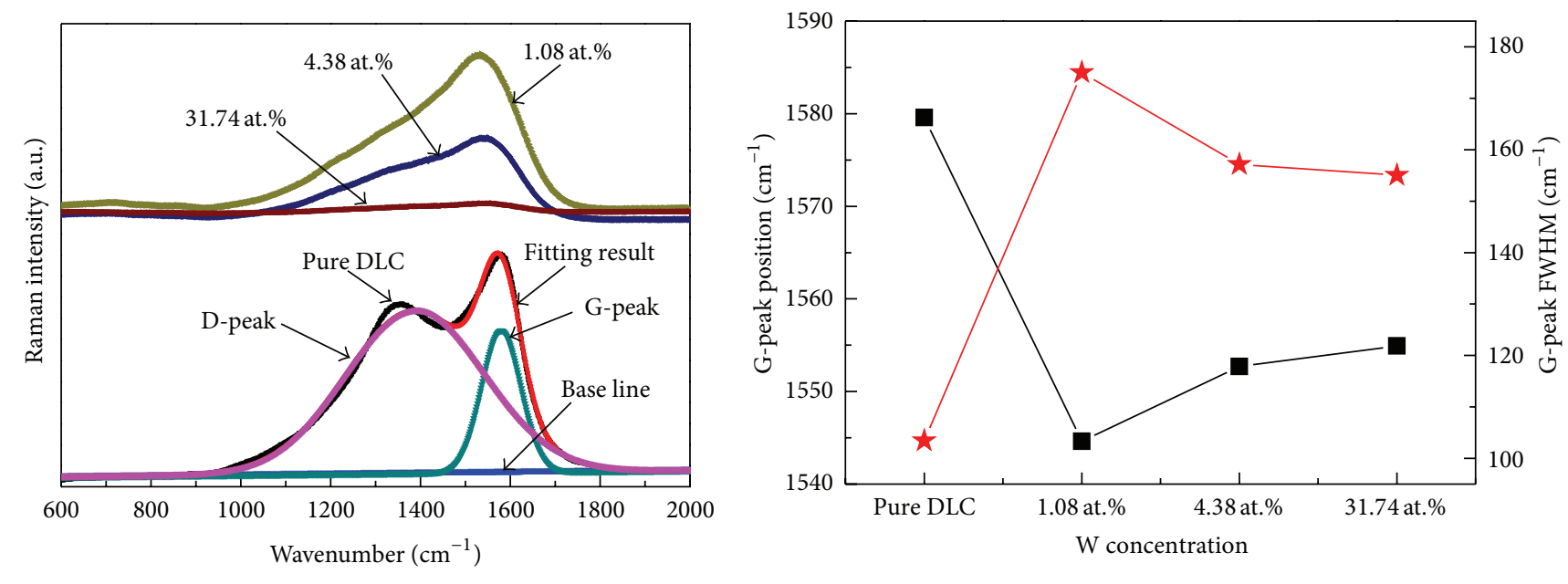

(a)
G-peak position G-peak FWHM (b)

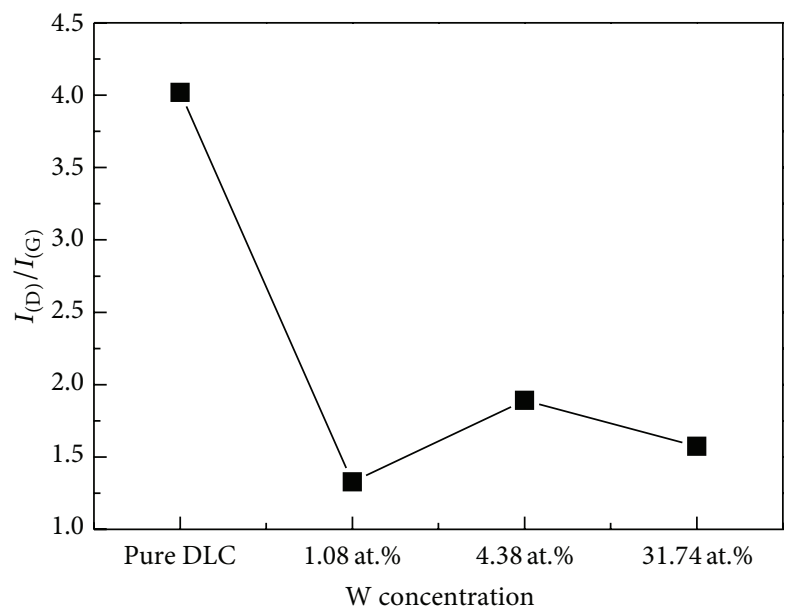

(c)

Figure 5: Typical Raman spectrum (a) and G FWHM and position (b), $I_{\mathrm{D}} / I_{\mathrm{G}}$ (c) of films with different W concentration.

(marked red circles) uniformly embedded in the DLC matrix, the sharp crystalline diffraction rings observed in Figure 4(d) indicated the existence of polycrystalline phases, which were identified to be the (111), (200), (220), (222), and (420) reflections of the cubic (FCC) $\mathrm{WC}_{1-x}$ structure. The TEM results indicated that the dissolved $\mathrm{W}$ atoms began to form $\mathrm{WC}_{1-x}$ phase in the DLC matrix when $\mathrm{W}$ concentration of the films was in the range of $1.08 \sim 4.38$ at.\%, and the films with higher $\mathrm{W}$ concentration were nanocomposite of $\mathrm{WC}_{1-x}$ particles embedded in the DLC matrix.

Raman is usually employed to characterize the atomic bonds of carbon films. Figure 5(a) displayed the Raman spectra of the W-C:H films at various W concentrations. Obviously, all samples presented a broad asymmetric Raman scattering band in the range of $1000-1700 \mathrm{~cm}^{-1}$, which was essentially as the typical carbon bond feature in hydrogenated amorphous carbons films. Raman spectroscopy can be generally deconvoluted into two peaks: one named G-peak at
$1580 \mathrm{~cm}^{-1}$ arising from $\mathrm{E}_{2 \mathrm{~g}}$ symmetry stretching vibration mode caused by the $\mathrm{sp}^{2}$ atom and the other named shoulder $\mathrm{D}$-peak at around $1360 \mathrm{~cm}^{-1}$ caused by the zone edge of $A_{1 g}$ breathing mode [1]. The experimental spectrum was fitted using two Gaussian peaks after background correction. According to the fitted G-peak position, the intensity ratio of D-peak to G-peak $\left(I_{\mathrm{D}} / I_{\mathrm{G}}\right)$, and the full width half maximum (FWHM) of the G-peak, the bonding structure of DLC films such as bond disorder, $\mathrm{sp}^{2} / \mathrm{sp}^{3}$ ratio can be derived qualitatively [41-43]. Figure 5(b) showed that when $\mathrm{W}$ concentration increased from 1.08 to 31.74 at.\%, the G peak position shifted monotonically from $1544.6 \mathrm{~cm}^{-1}$ to $1554.9 \mathrm{~cm}^{-1}$ and the $I_{\mathrm{D}} / I_{\mathrm{G}}$ ratio also increased from 1.32 to 1.57 as in Figure 5(c), implying a higher $\mathrm{sp}^{2} / \mathrm{sp}^{3}$ ratio in the W-C:H films with higher $\mathrm{W}$ concentration; however, the G-peak FWHM decreased from $175 \mathrm{~cm}^{-1}$ to $155 \mathrm{~cm}^{-1}$; it revealed that the degree of film structural disorder declined. But in comparison with the W-C:H films, the pure DLC film 


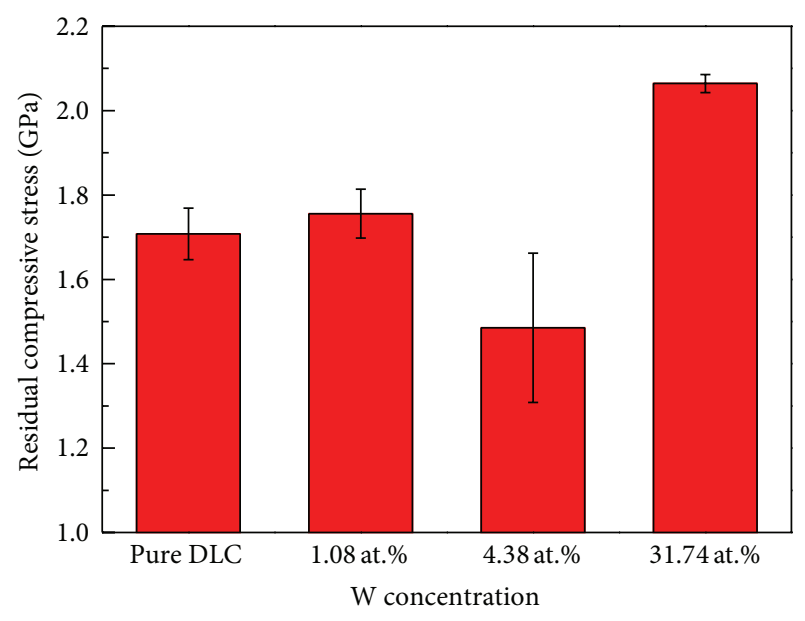

FIgURE 6: Residual compressive stress as a function of W concentration.

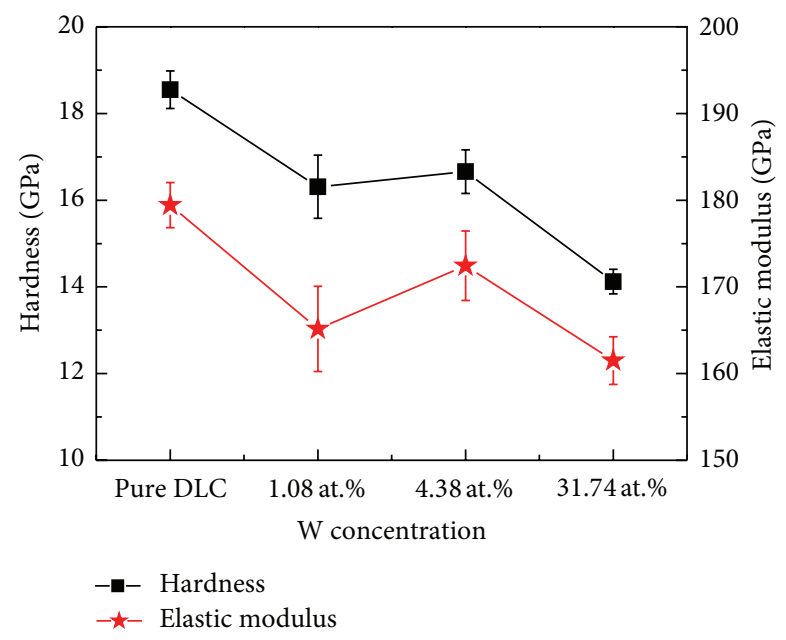

FIgURE 7: The hardness and elastic modulus as a function of the $\mathrm{W}$ concentration.

exhibited a higher $\mathrm{sp}^{2} / \mathrm{sp}^{3}$ ratio and less structural disorder, which may be due to the change of plasma caused by the collision between the $\mathrm{W}$ atoms with high energy and the carbon atoms; other researchers also discovered structure evolution due to influence of ion energy [44-46].

Figure 6 showed that the residual compressive stress in the pure DLC films was about $1.7 \mathrm{GPa}$ and arrived at $2.06 \mathrm{GPa}$ in $\mathrm{W}-\mathrm{C}: \mathrm{H}$ film with 31.74 at.\% W concentration; a minimum value about $1.485 \mathrm{GPa}$ was obtained when the $\mathrm{W}$ concentration was 4.38 at.\%, indicating that the residual compressive stress in the DLC films could be reduced in a proper range of $\mathrm{W}$ concentration. The decline of the film residual compressive stress could be explained by two stages. Firstly, at the lower $\mathrm{W}$ doping level, part of the $\mathrm{W}$ atoms was distributed in the DLC matrix without bonding with carbon atom, which provides the pivot location for the bond distortion and reduced the film compressive stress $[9,22]$. Moreover, the other few $\mathrm{W}$ atoms formed the nanocrystallites and embedded in the carbon matrix, which could also relax

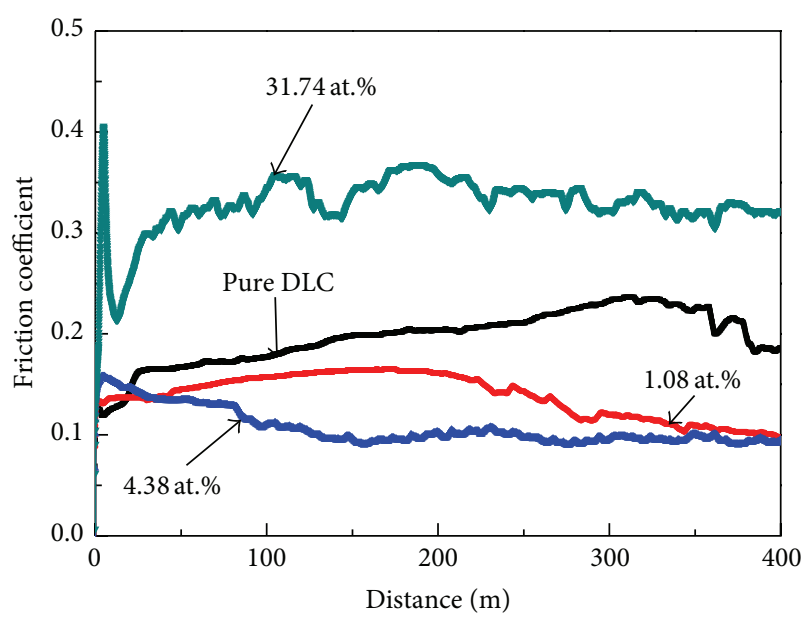

(a)

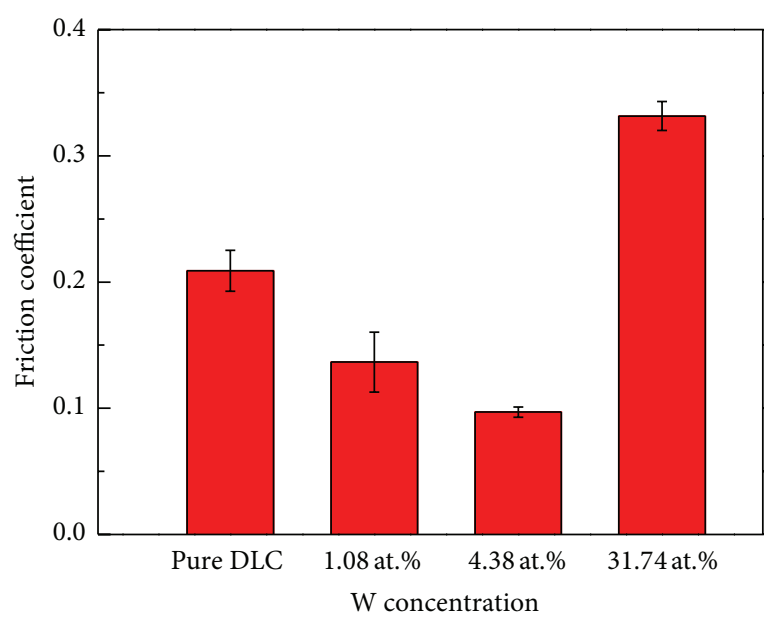

(b)

FIGURE 8: Friction coefficient (a) and average friction coefficient (b) in stable test condition of the films various $\mathrm{W}$ concentrations.

the stress by the diffusion and sliding of the grain boundary [11]. Since the $\mathrm{W}-\mathrm{C}$ bond length was longer than that of the $\mathrm{C}-\mathrm{C}$ bond; however, with further increasing the $\mathrm{W}$ concentration, more formation of W-C bond would induce the severe distortion of the atomic bond angles, which in turn increased the internal stress [9]. The present results agreed well with those reported by the others' work [17, 47].

Figure 7 depicted the hardness and elastic modulus as a function of the $\mathrm{W}$ concentration. It could be observed that, with more $\mathrm{W}$ atoms in the films, the hardness and elastic modulus of the films decreased from $18.5 \mathrm{GPa}$ to $14.12 \mathrm{GPa}$ and from $179.4 \mathrm{GPa}$ to $161.5 \mathrm{GPa}$, respectively. Generally, the mechanical properties of DLC films mainly depend on the $\mathrm{sp}^{3}$ carbon matrix [1], but the incorporation of $\mathrm{W}$ atoms and formation of nanoparticles in the DLC would break up the continuity of the carbon network, which would cause the decline of the hardness and elastic modulus. The similar phenomenon was also found in $\mathrm{Cr}-\mathrm{C}: \mathrm{H}$ and $\mathrm{Ti}-\mathrm{C}: \mathrm{H}$ films $[48,49]$. 
The friction coefficient of the films with sliding distance evolution and coefficient in stable test condition were shown in Figure 8. It indicated that W-C:H films with $\mathrm{W}$ atoms less than 4.38 at.\% had a lower friction coefficient compared with the pure DLC in the stable test condition. But when more $\mathrm{W}$ atoms were in the film, the friction coefficient of the film became larger than 0.3 , exhibiting the feature of tungsten carbide in the DLC matrix. Similar to the Cr element as a strong carbide former candidate doped in DLC films, other phenomena were also discovered in Cr-C:H films with different $\mathrm{Cr}$ concentration [50], which could be attributed to the formed hard $\mathrm{WC}_{1-x}$ phase in the DLC matrix [24]. The tribological property related with the microstructure influenced by $\mathrm{W}$ concentration was in accord with the results analyzed by XPS, SEM, and TEM.

\section{Conclusions}

The W-C:H films were prepared by a DC reactive magnetron sputtering with $\mathrm{W}$ target (99.99\%) in the Ar and $\mathrm{C}_{2} \mathrm{H}_{2}$ gas mixture. The concentration of tungsten in the films was varied from 1.08 at.\% to 31.74 at.\% by changing the sputtering current. The films mainly exhibited the feature of amorphous carbon when $\mathrm{W}$ concentration of the films was less than 4.38 at.\%. The solubility of the W atoms in the DLC films was in the range of $1.08 \sim 4.38$ at.\%. W atoms would bond with $\mathrm{C}$ atoms, resulting in the formation of $\mathrm{WC}_{1-x}$ nanoparticles with the $\mathrm{W}$ concentration exceeding the solubility. The films with 4.38 at. $\% \mathrm{~W}$ concentration showed a minimum value residual compressive stress, a higher hardness value, and better tribological properties.

\section{Acknowledgments}

The present research was financially supported by the programs of the State Key Project of Fundamental Research of China (nos. 2012CB933003, 2013CB632302) and the National Natural Science Foundation of China (51371187).

\section{References}

[1] J. Robertson, "Diamond-like amorphous carbon," Materials Science and Engineering R, vol. 37, no. 4-6, pp. 129-281, 2002.

[2] M. Lejeune, M. Benlahsen, and R. Bouzerar, "Stress and structural relaxation in amorphous hydrogenated carbon films," Applied Physics Letters, vol. 84, no. 3, pp. 344-346, 2004.

[3] E. Liu, L. Li, B. Blanpain, and J. P. Celis, "Residual stresses of diamond and diamondlike carbon films," Journal of Applied Physics, vol. 98, no. 7, Article ID 073515, 2005.

[4] T. Ma, Y.-Z. Hu, H. Wang, and X. Li, "Microstructural and stress properties of ultrathin diamondlike carbon films during growth: molecular dynamics simulations," Physical Review B, vol. 75, no. 3, Article ID 035425, 2007.

[5] O. A. Podsvirov, P. A. Karaseov, A. Y. Vinogradov et al., "Residual stress in diamond-like carbon films: role of growth conditions and ion irradiation," Journal of Surface Investigation, vol. 4, no. 2, pp. 241-244, 2010.

[6] K.-S. Kim, S.-H. Lee, Y.-C. Kim, S.-C. Lee, P.-R. Cha, and K.-R. Lee, "Structural analysis for the stress variation of ta-C film with deposition energy: a molecular dynamics simulation," Metals and Materials International, vol. 14, no. 3, pp. 347-352, 2008.

[7] L. Ji, H. Li, F. Zhao, J. Chen, and H. Zhou, "Microstructure and mechanical properties of Mo/DLC nanocomposite films," Diamond and Related Materials, vol. 17, no. 11, pp. 1949-1954, 2008.

[8] W. Dai and A. Wang, "Synthesis, characterization and properties of the DLC films with low Cr concentration doping by a hybrid linear ion beam system," Surface and Coatings Technology, vol. 205, no. 8-9, pp. 2882-2886, 2011.

[9] A.-Y. Wang, K.-R. Lee, J.-P. Ahn, and J. H. Han, "Structure and mechanical properties of $\mathrm{W}$ incorporated diamond-like carbon films prepared by a hybrid ion beam deposition technique," Carbon, vol. 44, no. 9, pp. 1826-1832, 2006.

[10] C.-C. Chen and F. C.-N. Hong, "Structure and properties of diamond-like carbon nanocomposite films containing copper nanoparticles," Applied Surface Science, vol. 242, no. 3-4, pp. 261-269, 2005.

[11] W. Dai and A. Wang, "Deposition and properties of Alcontaining diamond-like carbon films by a hybrid ion beam sources," Journal of Alloys and Compounds, vol. 509, no. 13, pp. 4626-4631, 2011.

[12] J. E. Krzanowski and J. L. Endrino, "The effects of substrate bias on phase stability and properties of sputter-deposited tungsten carbide," Materials Letters, vol. 58, no. 27-28, pp. 3437-3440, 2004.

[13] W. J. Meng and B. A. Gillispie, "Mechanical properties of Ticontaining and W-containing diamond-like carbon coatings," Journal of Applied Physics, vol. 84, no. 8, pp. 4314-4321, 1998.

[14] M. L. Terranova, V. Sessa, S. Piccirillo et al., "Temperaturedependent conduction of $\mathrm{W}$-containing composite diamond films," Applied Physics Letters, vol. 79, no. 13, pp. 2007-2009, 2001.

[15] N. Yao, A. G. Evans, and C. V. Cooper, "Wear mechanism operating in W-DLC coatings in contact with machined steel surfaces," Surface and Coatings Technology, vol. 179, no. 2-3, pp. 306-313, 2004.

[16] J. Veverkova and S. V. Hainsworth, "Effect of temperature and counterface on the tribological performance of W-DLC on a steel substrate," Wear, vol. 264, no. 7-8, pp. 518-525, 2008.

[17] C. W. Moura e Silva, J. R. T. Branco, and A. Cavaleiro, "How can $\mathrm{H}$ content influence the tribological behaviour of W-containing DLC coatings," Solid State Sciences, vol. 11, no. 10, pp. 1778-1782, 2009.

[18] T. Takeno, T. Komiyama, H. Miki, T. Takagi, and T. Aoyama, "XPS and TEM study of W-DLC/DLC double-layered film," Thin Solid Films, vol. 517, no. 17, pp. 5010-5013, 2009.

[19] A. L. Mohd Tobi, J. Ding, S. Pearson, S. B. Leen, and P. H. Shipway, "The effect of gross sliding fretting wear on stress distributions in thin W-DLC coating systems," Tribology International, vol. 43, no. 10, pp. 1917-1932, 2010.

[20] K. Baba, R. Hatada, and Y. Tanaka, "Preparation and properties of W-containing diamond-like carbon films by magnetron plasma source ion implantation," Surface and Coatings Technology, vol. 201, no. 19-20, pp. 8362-8365, 2007.

[21] T. Takeno, H. Miki, T. Takagi, and H. Onodera, "Electrically conductive properties of tungsten-containing diamond-like carbon films," Diamond and Related Materials, vol. 15, no. 11-12, pp. 1902-1905, 2006.

[22] A.-Y. Wang, H.-S. Ahn, K.-R. Lee, and J.-P. Ahn, "Unusual stress behavior in $\mathrm{W}$-incorporated hydrogenated amorphous carbon 
films," Applied Physics Letters, vol. 86, no. 11, Article ID 111902, 2005.

[23] S. Faruque Ahmed, K.-R. Lee, J.-I. Yoon, and M.-W. Moon, "Nanoporous structures of polyimide induced by Ar ion beam irradiation," Applied Surface Science, vol. 258, no. 8, pp. 38413845, 2012.

[24] X. Han, F. Yan, A. Zhang et al., "Structure and tribological behavior of amorphous carbon films implanted with $\mathrm{Cr}+$ ions," Materials Science and Engineering A, vol. 348, no. 1-2, pp. 319326, 2003.

[25] M.-W. Moon, S. H. Lee, J.-Y. Sun, K. H. Oh, A. Vaziri, and J. W. Hutchinson, "Wrinkled hard skins on polymers created by focused ion beam," Proceedings of the National Academy of Sciences of the United States of America, vol. 104, no. 4, pp. 11301133, 2007.

[26] Š. Meškinis, R. Gudaitis, V. Kopustinskas, and S. Tamulevičius, "Electrical and piezoresistive properties of ion beam deposited DLC films," Applied Surface Science, vol. 254, no. 16, pp. 52525256, 2008.

[27] F. Schwarz, G. Thorwarth, and B. Stritzker, "Synthesis of silver and copper nanoparticle containing a-C:H by ion irradiation of polymers," Solid State Sciences, vol. 11, no. 10, pp. 1819-1823, 2009.

[28] R. Kometani, K. Yusa, S. Warisawa, and S. Ishihara, "Piezoresistive effect in the three-dimensional diamondlike carbon nanostructure fabricated by focused-ion-beam chemical vapor deposition," Journal of Vacuum Science \& Technology B, vol. 28, no. 6, pp. F38-F41, 2010.

[29] S. Nakao, T. Soga, T. Sonoda, T. Asada, and N. Kishi, "Optical and electrical properties of nitrogen-doped diamond-like carbon films prepared by a bipolar-type plasma-based ion implantation," Japanese Journal of Applied Physics, vol. 51, no. 1, Article ID 01AC04, 2012.

[30] V. V. Zhurin, H. R. Kaufman, and R. S. Robinson, "Physics of closed drift thrusters," Plasma Sources Science and Technology, vol. 8, no. 1, pp. R1-R20, 1999.

[31] A. Anders, "Plasma and ion sources in large area coating: a review," Surface and Coatings Technology, vol. 200, no. 5-6, pp. 1893-1906, 2005.

[32] I. V. Bordenjuk, O. A. Panchenko, S. V. Sologub, and I. G. Brown, "Development of additional magnetron discharge in the drift region of an ion source with closed electron drift," Problems of Atomic Science and Technology, no. 6, pp. 168-170, 2008.

[33] D.-H. Park, J.-H. Kim, Y. Ermakov, and W.-K. Choi, "Linear ion source with closed drift and extended acceleration region," Review of Scientific Instruments, vol. 79, no. 2, Article ID 02B312, 2008.

[34] S. Lee, J.-K. Kim, and D.-G. Kim, "Effects of electrode geometry on the ion beam extraction of closed drift type anode layer linear ion source," Review of Scientific Instruments, vol. 83, no. 2, Article ID 02B703, 2012.

[35] W. Dai, H. Zheng, G. Wu, and A. Wang, "Effect of bias voltage on growth property of Cr-DLC film prepared by linear ion beam deposition technique," Vacuum, vol. 85, no. 2, pp. 231-235, 2010.

[36] H. Huang, G. H. Gilmer, and T. D. De La Rubia, "An atomistic simulator for thin film deposition in three dimensions," Journal of Applied Physics, vol. 84, no. 7, pp. 3636-3649, 1998.

[37] D. Bourgoin, S. Turgeon, and G. G. Ross, "Characterization of hydrogenated amorphous carbon films produced by plasmaenhanced chemical vapour deposition with various chemical hybridizations," Thin Solid Films, vol. 357, no. 2, pp. 246-253, 1999.
[38] P. Mérel, M. Tabbal, M. Chaker, S. Moisa, and J. Margot, “Direct evaluation of the sp3 content in diamond-like-carbon films by XPS," Applied Surface Science, vol. 136, no. 1-2, pp. 105-110, 1998.

[39] Y. Taki and O. Takai, "XPS structural characterization of hydrogenated amorphous carbon thin films prepared by shielded arc ion plating," Thin Solid Films, vol. 316, no. 1-2, pp. 45-50, 1998.

[40] J. Luthin and C. Linsmeier, "Carbon films and carbide formation on tungsten," Surface Science, vol. 454, no. 1, pp. 78-82, 2000.

[41] A. C. Ferrari and J. Robertson, "Interpretation of Raman spectra of disordered and amorphous carbon," Physical Review B, vol. 61, no. 20, pp. 14095-14107, 2000.

[42] A. C. Ferrari and J. Robertson, "Resonant raman spectroscopy of disordered, amorphous, and diamondlike carbon," Physical Review B, vol. 64, no. 7, Article ID 075414, 13 pages, 2001.

[43] C. Casiraghi, A. C. Ferrari, and J. Robertson, "Raman spectroscopy of hydrogenated amorphous carbons," Physical Review $B$, vol. 72, no. 8, Article ID 085401, 2005.

[44] I. Gerhards, C. Ronning, H. Hofsäss, M. Seibt, and H. Gibhardt, "Ion beam synthesis of diamond-like carbon thin films containing copper nanocrystals," Journal of Applied Physics, vol. 93, no. 2, pp. 1203-1207, 2003.

[45] J. L. Endrino, D. Horwat, R. Gago et al., "Electronic structure and conductivity of nanocomposite metal ( $\mathrm{Au}, \mathrm{Ag}, \mathrm{Cu}, \mathrm{Mo}$ )containing amorphous carbon films," Solid State Sciences, vol. 11, no. 10, pp. 1742-1746, 2009.

[46] Y.-H. Chan, C.-F. Huang, K.-L. Ou, and P.-W. Peng, "Mechanical properties and antibacterial activity of copper doped diamondlike carbon films," Surface and Coatings Technology, vol. 206, no. 6, pp. 1037-1040, 2011.

[47] S. J. Park, K.-R. Lee, D.-H. Ko, and K. Y. Eun, "Microstructure and mechanical properties of WC-C nanocomposite films," Diamond and Related Materials, vol. 11, no. 10, pp. 1747-1752, 2002.

[48] V. Singh, J. C. Jiang, and E. I. Meletis, “Cr-diamondlike carbon nanocomposite films: synthesis, characterization and properties," Thin Solid Films, vol. 489, no. 1-2, pp. 150-158, 2005.

[49] T. Sonoda, S. Nakao, and M. Ikeyama, "Deposition of Ti/C nano-composite DLC films by magnetron DC sputtering with dual targets," Vacuum, vol. 84, no. 5, pp. 666-668, 2009.

[50] W. Dai, P. Ke, and A. Wang, "Microstructure and property evolution of Cr-DLC films with different $\mathrm{Cr}$ content deposited by a hybrid beam technique," Vacuum, vol. 85, no. 8, pp. 792797, 2011. 

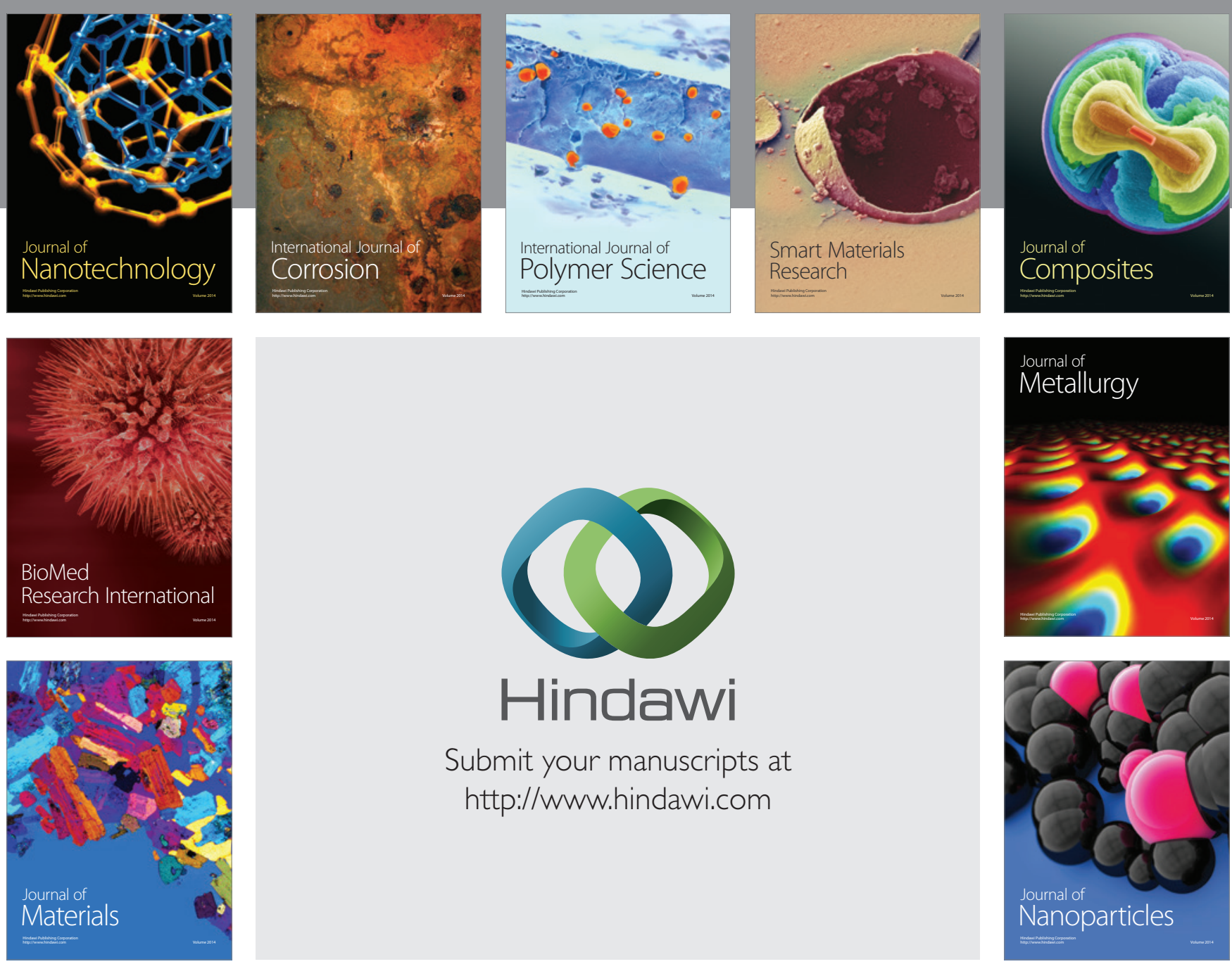

Submit your manuscripts at http://www.hindawi.com
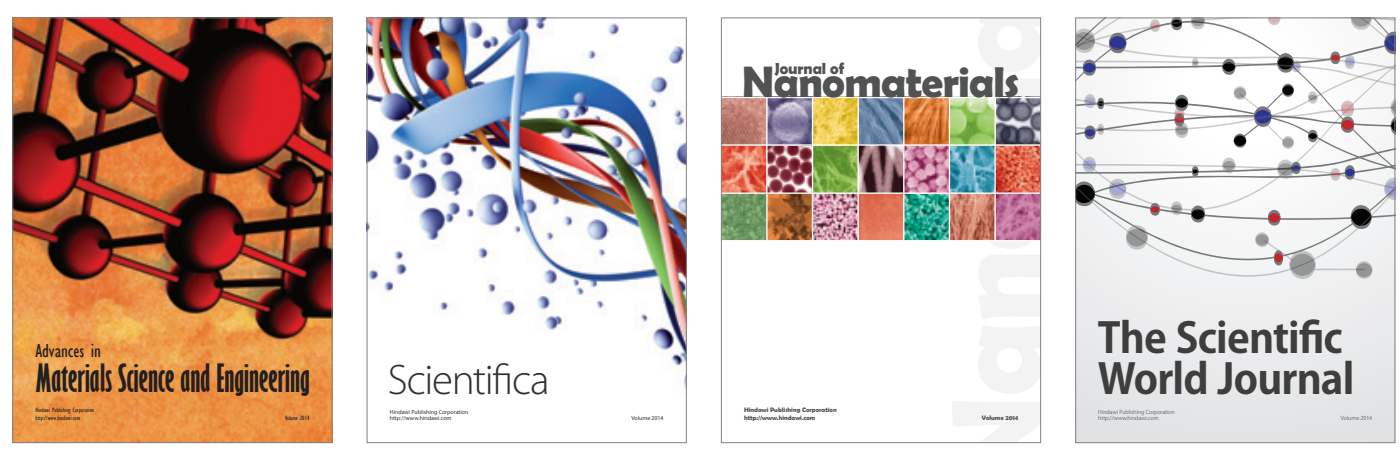

\section{The Scientific World Journal}
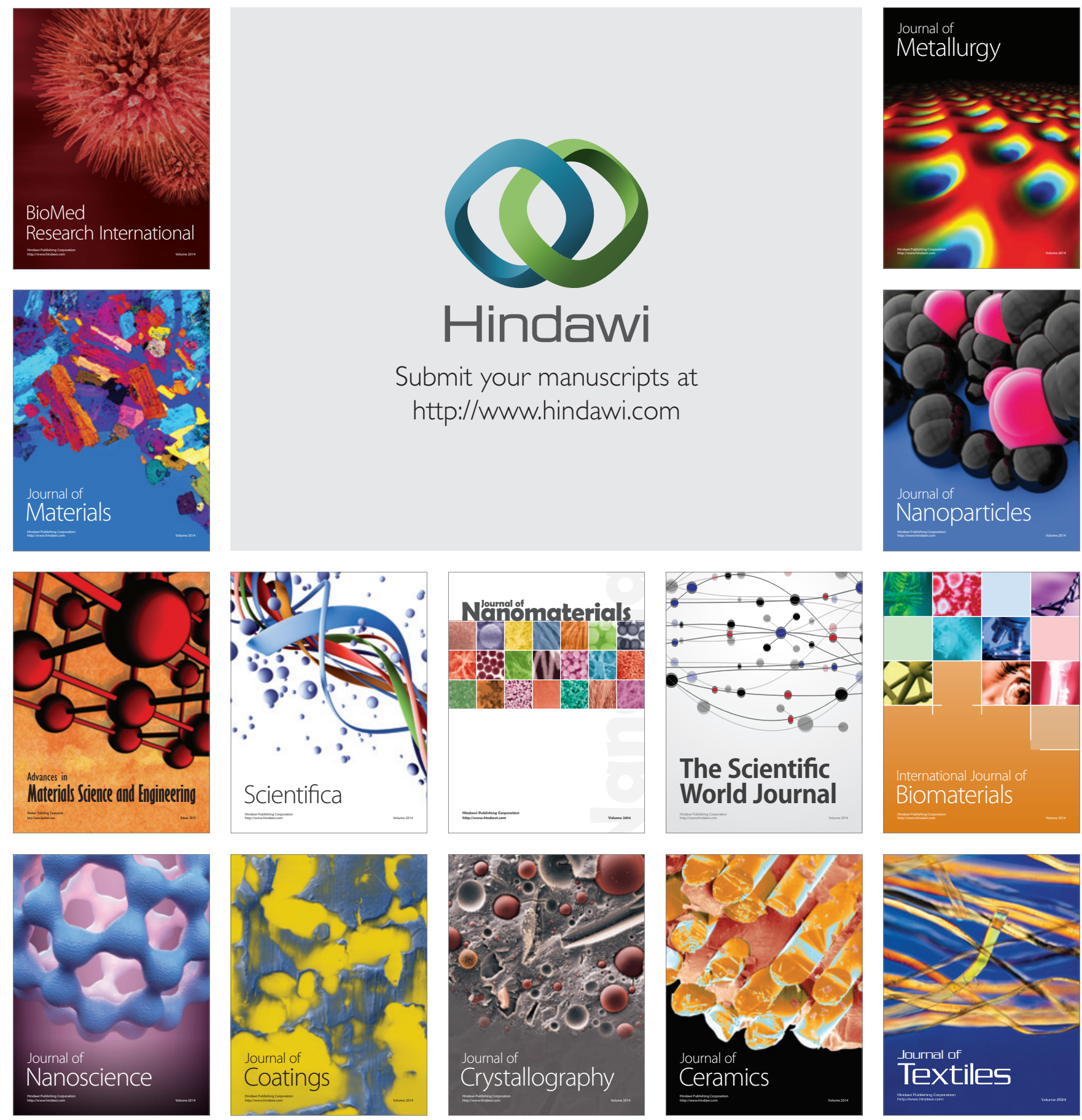